\title{
Revistas y mapas, brújulas y teclados: los editores y el canon
}

\author{
Journals and Maps, Compasses and Keyboards: Editors and the Canon \\ Revistas e mapas, bússolas e teclados: os editores e o cânon
}

\section{Saúl Sosnowski}

UNIVERSITY OF MARYLAND, COLLEGE PARK, ESTADOS UNIDOS

Profesor de Literatura y Cultura Latinoamericana de la Universidad de Maryland, College Park. PhD, University of Virginia. Fundador (1972) y director de la revista de literatura Hispamérica, que está en su $45^{\circ}$ año de publicación consecutiva. Es autor de fulio Cortázar: una búsqueda mítica, Borges y la Cábala: la búsqueda del Verbo (Noé, 1973), La orilla inminente: Escritores judíos-argentinos (Legasa, 1987), Borges y la Cábala: senderos del Verbo (Artes Gráficas, 2006; con Mirta Kupferminc), Fascismo y nazismo en las letras argentinas (Lumiére, 2009; con Leonardo Senkman), Cartografía de las letras hispanoamericanas; tejidos de la memoria (EDUVIM, 2015) y Borges, la letra y la Cábala (Centro de Arte Moderno de Madrid, 2016). Correo electrónico: sosnowsk@umd.edu

Ensayo

Documento accesible en línea desde la siguiente dirección: http://revistas.javeriana.edu.co Conferencia presentada en el "Primer Encuentro de Editores" de Latinoamericana. Asociación de Revistas Literarias y Culturales, sostenido en Santiago de Chile el 3 de agosto de 2015.

Cómo citar este ensayo:

Sosnowski, Saúl. "Revistas y mapas, brújulas y teclados: los editores y el canon". Cuadernos de Literatura 21.41 (2017): 62-67. https://doi.org/10.11144/Javeriana.cl21-41.rmbt 
Casi a mODo de epígrafe, quisiera compartir con ustedes una anécdota. Hace unos años tuve el privilegio de acompañar al entonces presidente de la Universidad de Maryland, un brillante ingeniero mecánico, en una visita a FANUC, una compañía japonesa ubicada al pie del Monte Fuji. Sus galpones, amplios e impecables, recibían cada tanto la visita de un par de supervisores uniformados. Los obreros eran robots que emitían un sonido suave y acompasado mientras producían otros robots. Fascinado por su perfección solo atiné a preguntar quién había creado el primer robot. Más que de ingeniería, es una pregunta de y para las humanidades, agregué mientras el ritmo robótico se instalaba en mi memoria.

El 10 de junio de 2015, la PLOS (Public Library of Science) publicó "El oligopolio de las editoriales académicas en la era digital" ("The Oligopoly of Academic Publishers in the Digital Era"). El escrito comienza con un dato histórico que merece ser tenido en cuenta. Nos recuerda que este año se cumple el $35^{\circ}$ aniversario de la creación de las revistas científicas. Fue en 1665 que aparecieron fournal des Sçavans y Philosophical Transactions en Francia e Inglaterra, respectivamente; publicaciones fundadas con el fin de impulsar el conocimiento científico al compartir los resultados que antes circulaban por medios más informales y, asimismo, para evitar la duplicación de experimentos análogos. De este modo, sostienen los autores del artículo (Vincent Larivière, Stefanie Haustein y Philippe Mongeon), se establecieron principios básicos para las prioridades científicas de la época y se promulgó, a la vez, la revisión de textos a cargo de pares.

Hecha esta referencia, los autores pasan a la presentación de datos basados en nada menos que 45 millones de documentos indexados en la Web of Science desde 1973 hasta 2013. Entre otros datos apuntan que en 2013 cinco editoriales (Reed-Elsevier, Wiley-Blackwell, Springer y Taylor \& Francis) concentraron más del 50\% de la difusión científica que se da a través de papers. Indican, además, que mientras las ciencias sociales se han concentrado en un $70 \%$ en esas editoriales, las humanidades se han mantenido "relativamente independientes" ${ }^{91}$ al tener allí solo un $20 \%$.

Comienzo con esta información por dos razones: la primera es señalar hasta qué punto el advenimiento de la era digital, particularmente desde mediados de los 9o, y la concentración del mundo editorial — es decir, de la difusión y el control

$1 \quad$ Ver: http://journals.plos.org/plosone/article?id=10.1371/journal.pone.0127502 
del conocimiento - afecta a nuestro propio espacio literario-cultural. La segunda es la declaración que surgió de la Revista chilena de literatura y de Anclajes, a la que muchos nos hemos suscripto. Volveré a ella más adelante.

Antes quisiera desglosar los términos que usé en el título de estos comentarios: "Revistas y mapas, brújulas y teclados: los editores y el canon". Creo que quienes hemos fundado y dirigimos revistas literarias y culturales compartimos siquiera algunas de las funciones y metas de los cartógrafos. Son diversos y múltiples los motivos que pudieron habernos impulsado a emprender esta tarea: presentar y promover una visión de mundo; formular una apuesta ideológica; desafiar lo dominante en un momento determinado mediante una plataforma contestataria; aportar alternativas a lo ya dibujado y asimilado; ofrecer un espacio a quienes carecen de otra opción... Por encima de toda otra motivación se trata de llamar la atención sobre otras rutas; sobre territorios que fueron soslayados, marginados o que han permanecido fuera de circuitos tantas veces transitados. Una revista es (¿puede ser / debería ser?) una apuesta a futuro; un diálogo de navegantes y, sí, hasta de navegantes un tanto aventureros. Solo así se evita reincidir en los mismos esquemas y los mismos hábitos críticos; los mismos autores, el agotamiento de autores consagrados porque garantizan el reconocimiento instantáneo, y la tácita aceptación de quienes comparten esos gustos, junto a ineludibles citas de quienes pautan la moda del momento.

Empecé con un dato varias veces centenario; el siguiente es un tanto más cercano a muchos de nosotros. Mientras arreciaba la fascinación por el estructuralismo (a veces más por su lado formulaico que por su veta creativa), así como por secuelas y ramificaciones que fijaban su propio rigor ante las letras americanas, cuatro directores de revistas académicas decidimos formar el Centro Internacional de Revistas de Crítica Literaria Latinoamericana. Las cuatro, a las que luego se sumaron algunas más, eran Escritura, dirigida desde Caracas por Ángel Rama; la Revista de crítica literaria latinoamericana, dirigida por Antonio Cornejo Polar, inicialmente desde Lima; Texto crítico, por Jorge Ruffinelli desde Xalapa, e Hispamérica. Lo que nos acercó fue el deseo y la necesidad de subrayar texto y contexto, literatura e historia, letras, voces y ciencias sociales: precisamente los procesos culturales cuya lectura estaba siendo devaluada en nombre de una aséptica precisión analítica. Si comparto con ustedes un momento que respondió a las batallas del canon - que se siguen dando con otro camuflaje e invocando otras banderas- es porque el contenido de cada una de nuestras publicaciones constituye una visión de mundo que ofrecemos a nuestros lectores (en muchísimos casos colegas y estudiantes 
universitarios), y que estas siguen portando juicios de valor e inciden en las relaciones que se forjan con el mundo que está tras las letras.

De ello han estado conscientes quienes individual o grupalmente publicaron revistas que son insoslayables para obtener un cuadro más comprehensivo, más generoso en su amplitud de miras, con el fin de entender la historia literaria y cultural del continente. Todos poseemos nuestra nómina de autores y obras canónicas; también hay revistas que el tiempo se ha encargado de confirmar como canónicas. Además de las publicaciones institucionales, valga este listado parcial de revistas que marcaron el siglo XX. Las menciono solo como ayuda memoria para que cada uno de nosotros vaya armando su propio modelo. Pienso en Martín Fierro, Proa, Nosotros, Sur, Revista de Antropofagia, Orígenes, Repertorio americano, Amauta, Contemporáneos, Marcha, Mito, Zona Franca, Casa de las Américas, Crisis, Plural/Vuelta, Punto de vista... Esta nómina que, por supuesto, es muy incompleta, basta, espero, para que tomemos nota de la importancia de nuestra tarea, y de que no todo se limita a las exigencias más perentorias de la academia ni a las aparentes urgencias del presente. Periódicamente aparecen publicaciones, se dan debates y se integran mesas redondas que nos recuerdan para qué sirven las revistas literarias. Pienso, por ejemplo, en la obra de Pablo Rocca sobre revistas del Río de la Plata; en el volumen de la Revista Iberoamericana que coordinaron Jorge Schwartz y Roxana Patiño sobre Revistas literarias/culturales del siglo $X X$, y en las ediciones facsimilares que edita la Biblioteca Nacional en Buenos Aires...

Decir política cultural, proclamas grupales, análisis críticos, páginas abiertas a nuevas voces - a la dinámica que hace a la producción literaria, presentación y perduración de renovadas modalidades, exigencia profesional y documentación precisa-, conforma algunas de las facetas que describen el trabajo que hoy nos convoca. Como en todo momento, estamos en épocas de transición. Es en este mundo, que ahora acotamos a la esfera académica, en donde se dirimen los debates en torno a lo que constituye la confiabilidad de la información; la legitimidad del saber. En muchos casos, más que hacia el saber, la preocupación se desvía hacia sus mecanismos de transmisión, y hacia la sanción de su valor a partir de parámetros que no siempre responden a nuestra geografía, ni al ejercicio, ni a las que considerábamos las metas y la razón de ser de las humanidades.

Es interesante notar que, si bien hay excepciones, la diversidad cultural del planeta se reduce a un común denominador cuando atravesamos los claustros universitarios; mejor dicho, para ser más precisos, sus oficinas administrativas. Innovation and Entrepreneurship, en la lengua que fuera, es el mantra de estos tiempos. Sumemos 'productividad', 'rendición de cuentas'(accountability), 'eficiencia', 
'impacto', 'acceso al mercado laboral'. Por supuesto que a estos ingredientes también se les adosa la excelencia académica y la competitividad: la promesa de una salida laboral. En el discurso de las autoridades universitarias se insiste en innovar, generar patentes, producir objetos para el mercado. Todo lo cual, en sí, no está nada mal, ni está reñido con las ambiciones decimonónicas que han sido organizadas en torno a la educación como impulsora de la industria, excepto que a lo largo de los años que el estudiante pasa en la universidad, se ha ido diluyendo el sentido mismo de la educación; la noción que de esa institución convendría que se graduara un ciudadano global, responsable, consciente de su lugar en la sociedad; un ciudadano que reconociera y apreciara el valor de las artes...

Aunque quizá no lo parezca a primera vista, las revistas literarias-culturales desempeñan un papel importante en estas consideraciones. Todos estamos interesados en incentivar y contribuir a la difusión de investigaciones académicas de calidad con el aval de pares - es lo que compartimos con las publicaciones científicas-. Pero me pregunto hasta qué punto la tecnificación y el afán de decir "nosotros medimos igual que ustedes, colegas de las ciencias duras y naturales", no ha comenzado a minar la especificidad de nuestro discurso y a hacernos dudar de la importancia del magisterio y de nuestra propia producción. Es cada vez más difícil hallar instituciones que reconozcan la importancia de las humanidades mediante asignaciones presupuestarias, si bien estas mantienen sus disciplinas a rienda corta porque, después de todo, son el espíritu, el alma de la institución. Y, como sabemos, resulta mucho más económico alimentar el alma que el cuerpo.

Tanto énfasis en la productividad de las ciencias y las ingenierías, en desmedro de lo que en otras épocas se consideraba las bases de una educación integral, lima presupuestos y también la autoestima de quienes están encargados de sembrar la duda; de cuestionar principios que se consideran axiomas cuando no lo son; de moverles el piso a quienes nos oyen y nos leen. Al margen de la creciente desintegración del Estado-Nación en varias regiones del planeta, se sigue diciendo que nuestra época está definida, y se seguirá definiendo, por la economía del conocimiento: the knowledge economy. La clave está en reconocer los parámetros y los alcances de ese conocimiento.

Desde hace unos lustros, centenares de universidades de EE.UU., Europa, América Latina, así como las nuevas y las más tradicionales de China y del sudeste asiático, se enfrentan a una exigencia cada vez más generalizada: la presión institucional por aparecer en los rankings internacionales. Al mismo tiempo, aun en el seno de los organismos que se ocupan de las mediciones, surgen las dudas y las protestas en cuanto a los factores que en última instancia fijan un número, un lugar, en la escala mundial o regional (en Latinoamérica tenemos nuestro propio 
ranking para no sucumbir del todo a su ausencia entre las 500 mejores universidades del mundo). El culto numerológico es preocupante cuando se trata de modelos de medición y de indicadores ajenos al saber; a los contenidos que nos interesa producir, publicar y difundir desde las humanidades y también a través de sus puentes con las ciencias sociales.

Excepto en las universidades creadas para suplir necesidades puntuales del mercado, o en las que por su origen y explícita misión académica se privilegian las ciencias y las ingenierías, el lugar cada vez más acotado de las humanidades ha sido espacio de la clausura de unidades académicas, de pronunciamientos, protestas y, finalmente, de una resignada aceptación de lo aparentemente inevitable. El hecho de que esta sea una tendencia mundial sirve como un llamado de atención en torno a una modalidad que ya tiene largas y nocivas repercusiones. Un aspecto se centra en la necesidad de cuestionar la utilización de un solo modelo para medir la calidad de las investigaciones, aclarando que no por ello dejaríamos de exigir y ejercer el rigor analítico idóneo al momento de evaluar notas, ensayos y libros. En el contexto que nos convoca me permito subrayar otro de los riesgos que corremos por el hecho de estar en el dominio académico: es el de tener tan presente la tecnificación que impone la autoridad universitaria, el de acatar como tan dominante el índice de citas al que se nos somete, que podamos llegar a olvidar la relación dialógica que subyace en la publicación de nuestras revistas.

Los textos que varios colegas de 'Latinoamericana' han compartido en los últimos meses apuntan a repensar la modalidad cuantificadora de la información, la métrica: toman nota de cierta incomodidad ante la presión por adoptar, más que adaptar, medidas que responden más a exigencias institucionales que a la producción de nuevos saberes. Es por eso que la "Declaración" que ha circulado en junio, con los consensuados "Acuerdos para las prácticas editoriales y académicas", ha sido adoptada por tantas revistas.

El objetivo explícito que nos convoca a estas jornadas es "el fortalecimiento editorial y académico de las revistas de la disciplina, sin olvidar un rol crítico en la definición y el desarrollo de la investigación universitaria" ${ }^{2}$ Entiendo que cada una de las áreas a ser consideradas tiene como subtexto, no solo el armado del material y su inscripción en la circulación internacional, sino que también incluye a sus destinatarios. Si bien las brújulas siempre apuntan al norte, Borges nos ha mostrado hacia dónde puede conducir una lectura errónea. Por otra parte, después de todo, nos debemos a nuestros lectores y es en su recepción en donde realmente se dirime el sentido de nuestras letras.

2 Ver: http://letras.uc.cl/html/13_noticias_destacados/noticias191.html 